\title{
Effects of Wind Power Technology Development on Large-scale VRE Generation Variability
}

Koivisto, Matti Juhani; Maule, Petr; Cutululis, Nicolaos Antonio; Sørensen, Poul Ejnar

Published in:

Proceedings of the 13th IEEE PowerTech Milano 2019: Leading innovation for energy transition

Link to article, DOI:

10.1109/PTC.2019.8810687

Publication date:

2019

Document Version

Peer reviewed version

Link back to DTU Orbit

Citation (APA):

Koivisto, M. J., Maule, P., Cutululis, N. A., \& Sørensen, P. E. (2019). Effects of Wind Power Technology Development on Large-scale VRE Generation Variability. In Proceedings of the 13th IEEE PowerTech Milano 2019: Leading innovation for energy transition IEEE. https://doi.org/10.1109/PTC.2019.8810687

\section{General rights}

Copyright and moral rights for the publications made accessible in the public portal are retained by the authors and/or other copyright owners and it is a condition of accessing publications that users recognise and abide by the legal requirements associated with these rights.

- Users may download and print one copy of any publication from the public portal for the purpose of private study or research.

- You may not further distribute the material or use it for any profit-making activity or commercial gain

- You may freely distribute the URL identifying the publication in the public portal 


\title{
Effects of Wind Power Technology Development on Large-scale VRE Generation Variability
}

\author{
Matti Koivisto, Petr Maule, Nicolaos Cutululis, Poul Sørensen \\ Department of Wind Energy \\ Technical University of Denmark \\ Roskilde, Denmark \\ mkoi@dtu.dk
}

\begin{abstract}
As variable renewable energy (VRE) shares are growing around the world, power systems are becoming more weather dependent. The weather driven variability in VRE generation can cause challenges to the operation and planning of power systems. This paper investigates how the expected technology development of wind power affects VRE generation variability over a large geographical area. A case study of Northern Europe is presented, where a mixture of offshore wind, onshore wind and solar photovoltaic generation is considered. Different scenarios with a doubling of today's annual VRE energy generation is modelled. The results show that modern wind turbine technology can significantly decrease the variability in aggregate VRE generation. When considering also an optimal mixture of different VRE sources, standard deviation of the aggregate VRE generation is estimated to be $31 \%$ lower compared to simply doubling existing installations.
\end{abstract}

Index Terms-- Optimization, solar, variable renewable energy, variance, wind.

\section{INTRODUCTION}

Variable renewable energy (VRE) generations, such as wind and solar power, are variable due to weather. As VRE generation shares increase, power systems become highly weather dependent. Compared to systems with mainly traditional generation, e.g., thermal and hydro, this variability can cause challenges to the operation and planning of power systems; such as planning of interconnection expansion, and system adequacy and balancing issues.

There exists a vast literature on wind power variability modelling, utilizing both reanalysis data [1]-[5] and stochastic simulation [6]-[8]. The geographical distribution of wind installations has a significant effect on the aggregate wind generation, and increasing the geographical spread can decrease the aggregate variability [5], [8]. When considering a mixture of VRE sources, the negative correlations between wind and solar PV generations can reduce the variance of the aggregate generation [9]-[11].

Integration of European power markets and subsequent interconnection of large geographical areas can decrease the

The work has been funded by the NSON-DK (Danish Energy Agency, EUDP, grant 64018-0032; previously ForskEL) and Flex4RES (Nordic Energy Research, grant 76084) projects. variability of aggregate VRE generation. Several papers show how the variance of aggregate VRE generation can be minimized considering both the geographical distribution of installations and optimal mixture of wind and solar PV. Meanvariance portfolio optimization was used for optimizing wind farm locations in a single country in [12], [13], and several European countries were analysed in [14], [15]. Similar analysis in [10], [11], considered also solar PV, and it was shown that a mixture of wind and solar is favorable when pursuing low aggregate VRE variability.

This paper models different VRE technology types in Northern Europe, and analyses the effect of their geographical distribution on the aggregate VRE generation variability. In addition, the effects of wind power technology development on the aggregate variability are studied. Both increasing hub heights and lower specific power are considered. Compared to analyzing only wind in [8], [12]-[15], this paper considers also solar PV in the optimal VRE generation mix. Compared to [10], [11], this paper includes the analysis of wind power technology development on the aggregate VRE variability. Following the approach in [11], variance of the overall aggregate generation, rather than ramp rate variance, is minimized. This is justified by the analysis of residual load behavior in the future in [16], where the additional ramping from VRE generation compared to load was considered modest in Nordic and Baltic countries.

35 years of simulated hourly wind and solar PV generation data are used to estimate the statistical parameters required for the aggregate VRE variance minimization. The simulations are carried out using the CorRES tool [5]. In addition to variance minimization, the full probability distributions of aggregate VRE generation and its ramp rates are studied.

The analysed countries are Denmark (DK), Finland (FI), Norway (NO), Sweden (SE), Estonia (EE), Lithuania (LT), Latvia (LV), Germany (DE), Netherlands (NL) and Poland (PL). The starting point are the VRE installation in 2016. The expected annual VRE energy from these installations is estimated; then, several scenarios for doubling the annual VRE energy are implemented and compared. It is shown that optimizing both the geographical distribution and mixture of the different VRE types lowers the aggregate variability 
significantly. Utilization of modern wind turbine technology further reduces the variability.

This paper is structured as follows. Section II provides a theoretical look at how aggregate variance can be minimized. Section III describes the VRE simulations to estimate the statistical parameters required for minimizing the variance. Section IV presents the results for the different scenarios. Section V provides discussion, and Section VI concludes the paper.

\section{AgGREGATE VARIANCE MinimisATION}

This section looks at how the statistical properties of the different VRE sources affect the variance of the aggregate generation. The minimization of the aggregate variance is then described.

\section{A. Aggregate Variance}

Considering $k$ sources of VRE generation, their aggregate generation at time $t$ is

$$
p_{t}=\sum_{i=1}^{k} w_{i} y_{i, t}
$$

where $w_{i}$ is the installed capacity (or weight) of source $i$, and $y_{i, t}$ is its standardized generation. Standardized generation gets values between 0 and 1 , where 1 means that the source is generating at full installed capacity.

As shown, e.g., in [11], the variance of the aggregate generation $p_{t}$ is

$$
\operatorname{Var}\left(p_{t}\right)=\sum_{i=1}^{k} w_{i}^{2} \sigma_{i}^{2}+2 \sum_{i \leq j \leq k} w_{i} w_{j} \sigma_{i} \sigma_{j} \rho_{i, j},
$$

where $\sigma_{i}^{2}=\operatorname{Var}\left(y_{i, t}\right)$ and $\rho_{i, j}=\operatorname{Cor}\left(y_{i, t}, y_{j, t}\right)$. Thus, the aggregate variance depends on the variances of the individual sources $\sigma_{i}^{2}$, on the correlations between the sources $\rho_{i, j}$, and of course on how much VRE generation is installed $w_{i}$. A VRE source can be, e.g., German solar PV generation or onshore wind generation in Norway.

\section{B. Constraints}

To minimize aggregate variance in (2), some constraints need to be fulfilled to ensure a realistic scenario. A scenario here means a set of VRE installations, i.e., a vector $\left[w_{1}, \ldots, w_{k}\right]^{\prime}$.

\section{1) Expected Annual VRE Energy}

Each VRE installation scenario reaches a specific expected annual VRE energy (assuming 8760 hours per year). As shown in [11], this constraint is specified as

$$
\left[\begin{array}{lll}
\mathrm{E}\left(y_{1, t}\right) & \ldots & \mathrm{E}\left(y_{k, t}\right)
\end{array}\right]\left[\begin{array}{c}
w_{1} \\
\vdots \\
w_{k}
\end{array}\right]=\frac{E_{\mathrm{a}}}{8760},
$$

where $E_{\mathrm{a}}$ is the expected annual VRE energy generated in the scenario. A scenario has installed capacity $w_{i}$ for each VRE source $i$, with expected value $\mathrm{E}\left(y_{i, t}\right)$. As $y_{i, t}$ are given as standardized generation, the expected values are capacity factors (CFs).

2) Lower and Upper Bounds for the Weights

VRE installation limits are assumed to be the same as used in [11]. The lower bounds for $\left[w_{1}, \ldots, w_{k}\right]^{\prime}$ are the installed capacities of 2016 (referred to as "today" in this paper); taken from the ENTSO-E Statistical Factsheet for 2016 [18].

The upper bounds for wind installations are taken mostly from the WindEurope 2030 high scenario [19]. However, for the Baltic countries the onshore wind installation limits were increased to $2 \mathrm{GW}$; and offshore wind limits were set as: $5 \mathrm{GW}$ for NO, $2 \mathrm{GW}$ for FI and SE, and 1.2 GW for the Baltic countries.

For solar PV, numbers from SolarPower Europe were used as the basis for the upper bounds for DE and NL, as described in [11]. To allow for some solar investments also in the north, the following upper limits were set: $5 \mathrm{GW}$ for Nordic countries and PL, and $2 \mathrm{GW}$ for the Baltic countries.

\section{Minimizing Aggregate Variance}

The variables $\sigma_{i}$ and $\rho_{i, j}$ in (2) are affected mostly by weather driven variability, although VRE technology does have some effect as described in Section III. However, within a technology scenario these variables, and the means in (3), are expected to remain constant. Thus, the weights $\left[w_{1}, \ldots, w_{k}\right]^{\prime}$ can be optimized to minimize (2). This means that the variance of the aggregate VRE generation is minimized in relation to the installed capacities of the different VRE sources. The minimization of was performed with Matlab function fmincon (Matlab R2016b, Optimization Toolbox [17]).

\section{VRE GENERATION SIMULATION}

This section describes the VRE generation simulations for estimating the statistical parameters required for (2) and (3). The differences in the statistical parameters in the different VRE technology cases are then presented.

\section{A. CorRES tool}

The VRE generation time series are simulated using the CorRES tool [5]. The simulations are a reanalysis of past weather covering 35 years with hourly resolution. The analyzed countries are shown in Fig. 1. VRE installation locations within each country are specified as in [11]. For onshore wind, existing installation locations were used. For those countries that do not have offshore wind installations today, planned locations were used [20]. Solar PV installations were assumed to be distributed throughout the countries, with more weight to the south for FI, NO and SE.

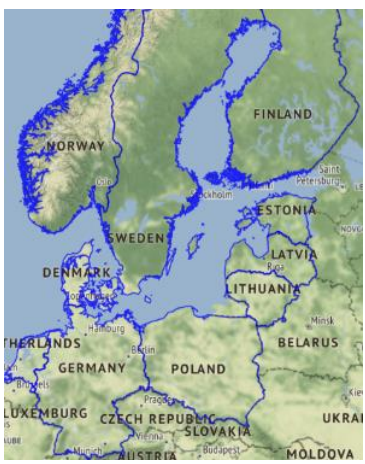

Fig. 1. The analysed countries. () EuroGeographics for the administrative boundaries. 


\section{B. VRE Technology Development}

Two VRE technology cases are analysed. In existing installations, the existing VRE installations are modelled. In future technology, development of VRE technology is considered, which changes the statistical properties used in the aggregate variance minimization.

Wind technology development is assumed to affect both hub heights and specific power. The future technology case assumes that all onshore wind hub heights will be $110 \mathrm{~m}$ and offshore wind $140 \mathrm{~m}$. Specific power is assumed to be $30 \%$ lower than the average specific power of the entire fleet today; the effect on power curve can be seen in Fig. 2. These technology development assumptions are discussed more in Section V. Solar PV technology is assumed to remain similar to today in the future; no changes are implemented.

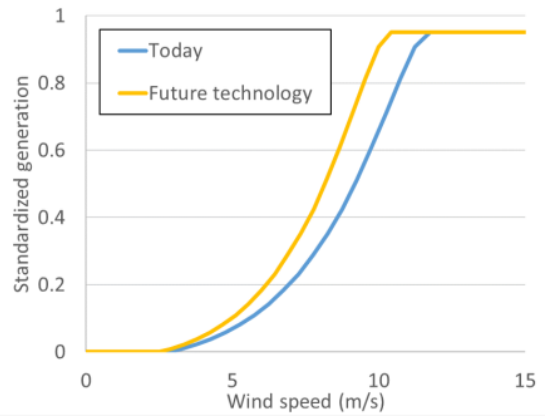

Fig. 2. Change in the power curve from today's fleet average to the future technology scenario with $30 \%$ lower specific power.

\section{Characteristics of Individual VRE Sources}

Some key statistics for the different VRE sources are given in Appendices A and B. Appendix A describes the existing installations case, whereas $\mathrm{B}$ shows results if all wind installations are as described in the previous subsection for future technology.

Appendices $\mathrm{A}$ and $\mathrm{B}$ show relative standard deviation (RSD), which is standard deviation (SD) divided by the mean, for each VRE source. A low RSD is favorable for reducing aggregate VRE variance when looking only at the behavior of the individual sources. It can be seen that wind has significantly lower RSDs than solar PV. Due to increased CFs, the future technology case shows lower RSD for each wind source compared to existing installations.

\section{Correlations Between the Sources}

Table I shows average correlations between the different VRE types (more detailed numbers can be found in Appendix C). Wind generations from the different countries are quite correlated, but correlation decreases when distance increases. All solar PV generations are highly correlated.

The negative correlations between solar PV and wind generations can be used in minimizing the variance of the aggregate VRE generation, as the $2 \sum_{i \leq j \leq k} w_{i} w_{j} \sigma_{i} \sigma_{j} \rho_{i, j}$ part of (2) can be negative. Interestingly, the negative correlations between onshore wind and solar PV are stronger in the future technology case than with existing installations, as can be seen in Table I. Other correlations remain quite similar.

\begin{tabular}{|c|c|c|c|}
\hline & Onshore wind & Offshore wind & Solar PV \\
\hline Onshore wind & $0.41(0.41)$ & $0.39(0.42)$ & $-0.24(-0.18)$ \\
\hline Offshore wind & $0.39(0.42)$ & $0.34(0.38)$ & $-0.14(-0.14)$ \\
\hline Solar PV & $-0.24(-0.18)$ & $-0.14(-0.14)$ & $0.92(0.92)$ \\
\hline
\end{tabular}

The first values are for the future technology case (based on Appendix C); the values in the brackets are for existing installations.

\section{RESULTS}

This section presents the different scenarios analysed, and compares the behavior of aggregate VRE generation in them.

\section{A. Studied Scenarios}

The VRE installations for a "today" scenario are taken from the ENTSO-E Statistical Factsheet for 2016 [18]. Compared to "today", all other scenarios achieve a doubling of the expected annual VRE energy (3). The "today doubled" scenario achieves this by simply doubling all the installations in the "today" scenario. Both scenarios use existing installations.

Two optimized scenarios, where the aggregate VRE generation variance (2) is minimized while respecting the constraints specified in Section II B, are created. The "optimized (existing installations)" scenario achieves this assuming existing installations. The "optimized (future installations)" scenario minimizes (2) assuming that all VRE installation are as presented in Section III B for future technology.

\section{B. Aggregate VRE Variance in the Scenarios}

The optimized frontier in Fig. 3 shows that some increase in annual VRE energy can be achieved with only a small increase in the aggregate VRE generation SD. However, as installed capacities of the most favorable VRE sources start to reach their upper limits, the SD increases faster when annual VRE energy increases. The optimized frontier is given for existing installations, and no point can lie on the left side of the frontier when this technology scenario is considered. However, future technology allows for a lower aggregate SD with the same annual VRE energy, as can be see for the "optimized (existing installations)" scenario; this is possible because the statistics $\sigma_{i}, \rho_{i, j}$ and $\mathrm{E}\left(y_{i, t}\right)$ used for (2) and (3) change compared to existing installations.

As the "today doubled" scenario is simply a scaled-up version of "today", SD of the aggregate VRE generation is double compared to "today", as can be seen in Table II. The optimization of the weights of the different VRE sources lowers the aggregate SD by $19 \%$ compared to "today doubled" (when assuming existing installations). Considering future technology for the VRE sources decreases the aggregate SD significantly; the "optimized (future technology)" scenario, where both optimal mixture of VRE sources and wind technology development are considered, provides a $31 \%$ decrease in aggregate VRE generation SD compared to "today doubled“". 


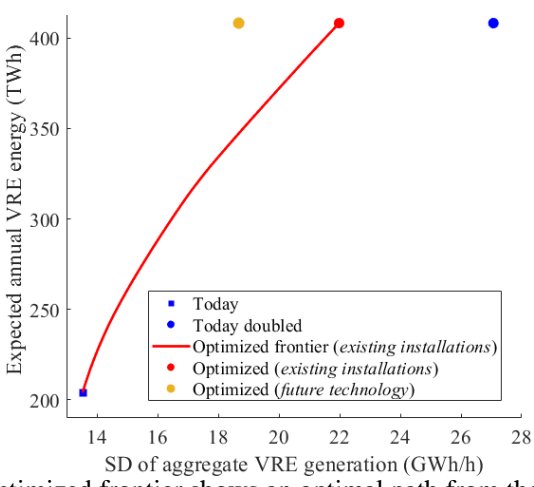

Fig. 3. The optimized frontier shows an optimal path from the annual VRE energy generation of "today" to its doubling when assuming existing installations. The "optimized (future technology)" scenario considers both optimal mixture of VRE sources and wind technology development.

TABLE II. OVERALL RESUlTS OF THE SCENARIOS

\begin{tabular}{|c|c|c|}
\hline Scenario & $\begin{array}{c}\text { SD of } \\
\text { aggregate } \\
\text { (GWh/h) }\end{array}$ & $\begin{array}{c}\text { Expected } \\
\text { annual VRE } \\
\text { energy (TWh) }\end{array}$ \\
\hline Today & 13.5 & 204 \\
\hline Today doubled & 27.1 & 408 \\
\hline Optimized (existing installations) & 22.0 & 408 \\
\hline Optimized (future technology) & 18.7 & 408 \\
\hline
\end{tabular}

\section{The Optimized Weights}

Fig. 4 shows a country-wise view of the optimized VRE installations in the "today" and the two optimized scenarios (more detailed numbers are given in Appendix D). The optimization puts no more installations in DE, as there are already significant VRE installations. Rather, the optimization chooses to put much of the additional VRE installations far away from the areas with high existing VRE installations; e.g., to FI, EE and NO. These countries show low correlations to wind generation in DE, as can be seen in Appendix D and on a regional level in Fig. 5.

The "optimized (future technology)" scenario achieves the same annual VRE energy as the "optimized (existing technology)" with less VRE installations, as the wind CFs are higher (as can be seen in the appendices). The optimization sees value in utilizing a mixture of wind and solar PV in both optimized scenarios.

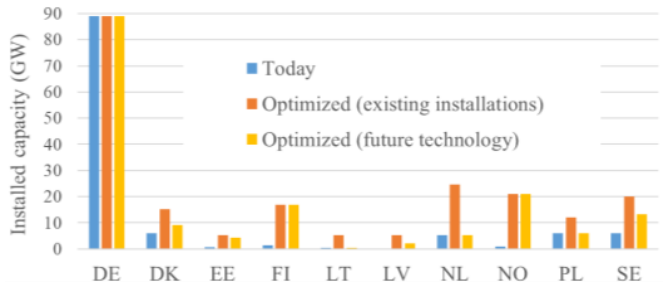

Fig. 4. The sums of installed VRE generation capacities in the different countries; more detailed numbers are given in Appendix D.

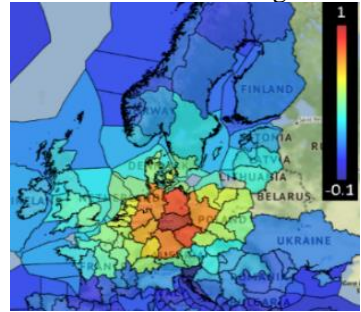

Fig. 5. Spatial correlations in wind generation looking from an example German onshore region (using the 35 years of simulated hourly data).

\section{A Look at the Full Probability Distributions}

Fig. 6 shows the probability distribution functions (PDFs) of aggregate VRE generation in the "today doubled" and both optimized scenarios. In addition to lower SD, the optimized scenarios have the $5^{\text {th }}$ and $95^{\text {th }}$ percentiles closer to the mean of the aggregate VRE generation compared to "today doubled"; this can be seen also in Table III. Utilization of future technology significantly reduces the aggregate VRE generation variability compared to existing installations.

Fig. 7 shows that in addition to aggregate VRE variability, the optimized scenarios show also lower aggregate hourly VRE ramping compared to the "today doubled" scenario. Table III shows that the ramp rate SDs are smaller, and the $5^{\text {th }}$ and $95^{\text {th }}$ percentiles are closer to zero compared to "today doubled". Use of future technology reduces the aggregate VRE ramping compared to existing installations.

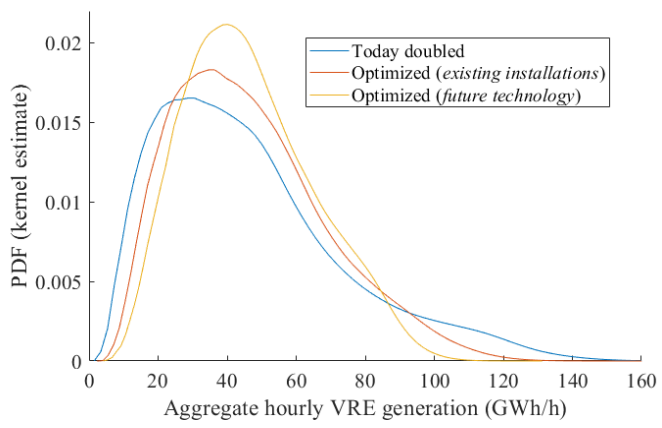

Fig. 6. Estimated PDFs of the aggregate VRE generation for the "today doubled" and the two optimized scenarios.

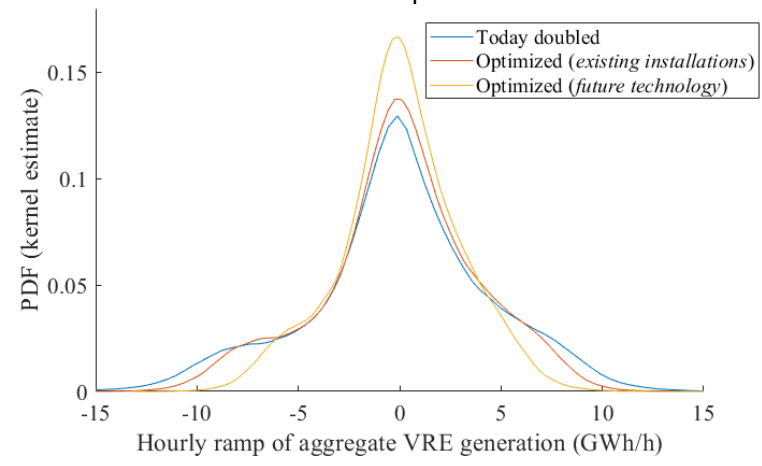

Fig. 7. Estimated PDFs of the aggregate VRE generation hourly ramping for the "today doubled" and the two optimized scenarios.

TABLE III. STATISTICS FOR THE SCENARIOS

\begin{tabular}{|c|c|c|c|}
\hline Scenario & $\begin{array}{c}\mathbf{5}^{\text {th }}, \mathbf{9 5}^{\text {th }} \\
\text { percentile } \\
(\mathbf{G W h} / \mathbf{h})\end{array}$ & $\begin{array}{c}\text { Ramp } \\
\text { rate SD } \\
(\mathbf{G W h} / \mathbf{h})\end{array}$ & $\begin{array}{c}\mathbf{5}^{\text {th }} \mathbf{9 5}^{\text {th }} \text { ramp } \\
\text { rate percentile } \\
(\mathbf{G W h} / \mathbf{h})\end{array}$ \\
\hline Today doubled & $12.5,103$ & 4.52 & $-8.39,7.56$ \\
\hline $\begin{array}{c}\text { Optimized } \\
\text { (existing installations) }\end{array}$ & $16.4,88.6$ & 3.91 & $-7.35,6.52$ \\
\hline $\begin{array}{c}\text { Optimized } \\
\text { (future technology) }\end{array}$ & $19.3,81.0$ & 3.02 & $-5.50,5.04$ \\
\hline
\end{tabular}

\section{DISCUSSION}

The modelled future VRE technology development assumes that all wind installations are as described in Section III B for future technology. This means that in addition to all new installations, the existing installations are repowered with high hub heights and modern turbines. This can be challenging especially for onshore wind, where allowed hub height limits 
can be an issue. However, the future technology case still shows the possibilities of technology development in reducing VRE variability.

In the analyses presented in this paper, grid constraints are not considered. While the per-country VRE installation limits were considered feasible, grid constraints should be considered in the future. Also, dynamic studies of the scenarios are required to properly assess their feasibility.

Future work should also consider load to enable analysis of residual load variability [16]. Although it is possible to modify (2) to minimize residual load variance, it was not done in this paper as only a few years of load time series were available from the different countries. Future work can consider how a combination of statistical load modelling (e.g., [21]) and the 35 years of available meteorological reanalysis data (including, e.g., temperature) could be utilized to provide also load reanalysis data (in addition to VRE reanalysis data).

\section{CONCLUSION}

This paper has studied the effects of wind power technology development on aggregate VRE variability. Different scenarios with a doubling of today's annual VRE energy generation were modelled for a case study in Northern Europe. When both the optimal mixture of VRE sources and the wind technology development are considered, a $31 \%$ decrease in the aggregate VRE generation SD is expected compared to simply scaling up today's VRE installations.

The optimized scenarios, both modelling with current VRE installations and when considering wind technology development, use a mixture of offshore wind, onshore wind and solar PV. Although wind shows lower RSDs in the individual countries than solar, the negative correlations between solar PV and wind generation make having a mixture of wind and solar favorable. The optimized scenarios have VRE installations more geographically spread than the installations of today.

In addition to minimizing the variance of aggregate VRE generation, the optimized scenarios show significantly reduced probabilities of very high or low aggregate VRE generation, and reduced ramp rates compared to simply doubling today's VRE installations. When considering wind power technology development, the ramp rates are reduced compared to modelling with current VRE installations.

The results highlight the importance of considering expected VRE technology development when assessing variability of large-scale VRE generation in the future. Also, the results on the optimal geographical distribution of VRE installations highlight the importance of analyzing larger geographical regions than single countries when planning future power and energy systems. The results can be used, e.g., when considering market structures and policies incentivizing future VRE installations.

\section{REFERENCES}

[1] I. González-Aparicio, F. Monforti, P. Volker, A. Zucker, F. Careri, T. Huld and J. Badger, "Simulating European wind power generation applying statistical downscaling to reanalysis data," Applied Energy, vol. 199, pp. 155-168, August 2017.
[2] I. Staffell and S. Pfenninger, "Using bias-corrected reanalysis to simulate current and future wind power output," Energy, vol. 114, pp. 1224-1239, November 2016.

[3] J. Olauson and M. Bergkvist, "Modelling the Swedish wind power production using MERRA reanalysis data", Renewable Energy, vol. 76, pp. 717-725, April 2015.

[4] E. Nuño, P. Maule, A. Hahmann, N. Cutululis, P. Sørensen and I. Karagali, "Simulation of transcontinental wind and solar PV generation time series," Renewable Energy, vol. 118, pp. 425-436, April 2018.

[5] M. Koivisto, K. Das, F. Guo, P. Sørensen, E. Nuño, N. Cutululis and P. Maule, "Using time series simulation tool for assessing the effects of variable renewable energy generation on power and energy systems," WIREs Energy and Environment, e329, 2018.

[6] D. Villanueva, A. Feijóo, and J. L. Pazos, "Simulation of correlated wind speed data for economic dispatch evaluation," IEEE Transactions on Sustainable Energy, vol. 3, no. 1, January 2012.

[7] B. Klöckl and G. Papaefthymiou: "Multivariate time series models for studies on stochastic generators in power systems," Renewable Energy, vol. 80, no. 3, pp. 265-276, Mar. 2010.

[8] M. Koivisto, J. Ekström, J. Seppänen, I. Mellin, J. Millar, and L. Haarla, "A statistical model for comparing future wind power scenarios with varying geographical distribution of installed generation capacity", Wind Energy, vol. 19, pp. 665-679, May 2016.

[9] J. Ekström, M. Koivisto, I. Mellin, R. J. Millar and M. Lehtonen “A Statistical Model for Hourly Large-Scale Wind and Photovoltaic Generation in New Locations," IEEE Transactions on Sustainable Energy, vol. 8, no. 4, pp. 1383-1393, October 2017.

[10] N. S. Thomaidis, F. J. Santos-Alamillos, D. Pozo-Vázquez and J. UsaolaGarcía, "Optimal management of wind and solar energy resources," Computers \& Operations Research, vol. 66, pp. 284-291, February 2016.

[11] M. Koivisto, N. Cutululis and J. Ekström, "Minimizing Variance in Variable Renewable Energy Generation in Northern Europe," IEEE International Conference on Probabilistic Methods Applied to Power Systems, Boise, Idaho USA, June 2018.

[12] F. J. Santos-Alamillos, N. S. Thomaidis, J. Usaola-García d, J. A. RuizArias, and D. Pozo-Vazquez, "Exploring the mean-variance portfolio optimization approach for planning wind repowering actions in Spain," Renewable Energy, vol. 106, pp., 335-342, June 2017.

[13] C. J. Joubert, and H. J. Vermeulen, "Optimisation of Wind Farm Location Using Mean-Variance Portfolio Theory and Time Series Clustering", IEEE International Conference on Power and Energy, June 2016, Melaka, Malaysia.

[14] C. Tejeda, C. Gallardo, M. Domínguez, M. Á. Gaertner, C, Gutierrez and M. de Castro, "Using wind velocity estimated from a reanalysis to minimize the variability of aggregated wind farm production over Europe," Wind Energy, vol. 21, no. 3, pp. 174-183, March 2018.

[15] F. Roques, C. Hirou and M. Saguan, "Optimal wind power deployment in Europe-A portfolio approach," Energy Policy, vol. 38, no. 7, pp. 3245-3256, July 2010.

[16] M. Koivisto, P. Maule, E. Nuño, P. Sørensen and N. Cutululis, "Statistical Analysis of Offshore Wind and other VRE Generation to Estimate the Variability in Future Residual Load," Journal of Physics: Conference Series, vol. 1104, no. 1, 012011, 2018.

[17] Matlab Optimization Toolbox Documentation [Online]. Available: se.mathworks.com/help/optim/index.html (referenced 26 Nov 2018)

[18] ENTSO-E Statistical Factsheets webpage [Online]. Available: https://www.entsoe.eu/publications/statistics/statisticalfactsheet/Pages/default.aspx (referenced 27 Nov 2018)

[19] WindEurope. (2017, September). Wind energy in Europe: Scenarios for 2030. [Online]. Available: https://windeurope.org/wpcontent/uploads/files/about-wind/reports/Wind-energy-in-EuropeScenarios-for-2030.pdf (referenced 27 Nov 2018).

[20] 4C offshore wind farm database [Online]. Available: http://www.4coffshore.com/windfarms/ (referenced 27 Nov 2018).

[21] M. Koivisto, M. Degefa, M. Ali, J. Ekström, J. Millar, M. Lehtonen, "Statistical Modeling of Aggregated Electricity Consumption and Distributed Wind Generation in Distribution Systems Using AMR Data," Electric Power Systems Research, vol. 129, pp. 217-226, December 2015. 
APPENDIX A: DESCRIPTIVE STATISTICS OF INDIVIDUAL VRE SOURCES WITH EXISTING INSTALLATIONS

\begin{tabular}{|c|c|c|c|c|c|c|c|c|c|c|c|c|c|c|c|c|c|c|c|c|c|c|c|c|c|c|c|c|c|c|}
\hline & \multicolumn{10}{|c|}{ Onshore wind } & \multicolumn{10}{|c|}{ Offshore wind } & \multicolumn{10}{|c|}{ Solar PV } \\
\hline & DE & DK & $\mathbf{E E}$ & FI & LT & \begin{tabular}{|l|l} 
LV & I
\end{tabular} & $\mathrm{NL}$ & NO & PL & SE & DE & DK & EE & FI & LT & LV & $\mathrm{NL}$ & NO & PL & SE & DE & DK & EE & FI & LT & LV & NL & NO & PL & SE \\
\hline Mean & 0.22 & 0.24 & 0.26 & 0.25 & \begin{tabular}{|l|l|} 
& 0.25 \\
\end{tabular} & \begin{tabular}{|l|}
0.26 \\
\end{tabular} & \begin{tabular}{|l|} 
\\
\end{tabular} & \begin{tabular}{|l|}
0.28 \\
\end{tabular} & 0.24 & 0.29 & 0.43 & 0.43 & 0.29 & 0.30 & 0.36 & 0.34 & \begin{tabular}{|l|}
0.40 \\
\end{tabular} & 0.41 & 0.35 & 0.34 & \begin{tabular}{|l|}
0.12 \\
\end{tabular} & 0.12 & 0.12 & \begin{tabular}{|l|}
0.09 \\
\end{tabular} & 0.12 & 0.12 & 0.10 & 0.10 & 0.10 & 0.11 \\
\hline SD & 0.20 & 0.24 & 0.24 & \begin{tabular}{|l|}
0.22 \\
\end{tabular} & \begin{tabular}{|l|l|} 
& 0.25 \\
\end{tabular} & \begin{tabular}{|l|}
0.26 \\
\end{tabular} & 0.25 & \begin{tabular}{|l|}
0.19 \\
\end{tabular} & 0.21 & \begin{tabular}{|l|}
0.19 \\
\end{tabular} & 0.32 & 0.30 & \begin{tabular}{|l|l|} 
& 0.30 \\
\end{tabular} & 0.27 & 0.32 & 0.32 & 0.31 & \begin{tabular}{|l|}
0.28 \\
\end{tabular} & 0.31 & \begin{tabular}{|l|} 
\\
\end{tabular} & 0.16 & 0.18 & 0.19 & 0.14 & 0.19 & 0.18 & 0.15 & 0.15 & 0.14 & 0.16 \\
\hline RSD & 0.88 & 0.97 & 0.93 & \begin{tabular}{|l|}
0.86 \\
\end{tabular} & 1.00 & \begin{tabular}{|l|}
1.00 \\
\end{tabular} & \begin{tabular}{|l|}
0.98 \\
\end{tabular} & \begin{tabular}{|l|}
0.69 \\
\end{tabular} & \begin{tabular}{|c|}
0.87 \\
\end{tabular} & \begin{tabular}{|l|}
0.67 \\
\end{tabular} & 0.73 & 0.70 & \begin{tabular}{|l|}
1.04 \\
\end{tabular} & \begin{tabular}{|l|}
0.89 \\
\end{tabular} & \begin{tabular}{|l|}
0.91 \\
\end{tabular} & \begin{tabular}{|l|}
0.95 \\
\end{tabular} & \begin{tabular}{|l|}
0.78 \\
\end{tabular} & \begin{tabular}{|l|}
0.69 \\
\end{tabular} & \begin{tabular}{|l|}
0.89 \\
\end{tabular} & \begin{tabular}{|l|}
0.65 \\
\end{tabular} & \begin{tabular}{|l|}
1.42 \\
\end{tabular} & 1.52 & \begin{tabular}{|l|}
1.56 \\
\end{tabular} & \begin{tabular}{|l|}
1.60 \\
\end{tabular} & 1.52 & 1.54 & \begin{tabular}{|l|}
1.48 \\
\end{tabular} & 1.52 & 1.45 & 1.54 \\
\hline
\end{tabular}

These numbers relate to existing installations; mean is the same as CF of the VRE source.

APPENDIX B: DESCRIPTIVE STATISTICS OF INDIVIDUAL VRE SOURCES WITH FutURE TECHNOLOGY

\begin{tabular}{|c|c|c|c|c|c|c|c|c|c|c|c|c|c|c|c|c|c|c|c|c|c|c|c|c|c|c|c|c|c|c|}
\hline & \multicolumn{10}{|c|}{ Onshore wind } & \multicolumn{10}{|c|}{ Offshore wind } & \multicolumn{10}{|c|}{ Solar PV } \\
\hline & DE & DK & EE & FI & \begin{tabular}{|l|} 
LT \\
\end{tabular} & \begin{tabular}{|l|}
$\mathbf{L V}$ \\
\end{tabular} & NL & NO & PL & SE & DE & DK & EE & FI & \begin{tabular}{|l|}
$\mathbf{L T}$ \\
\end{tabular} & $\mathbf{L V}$ & NL & NO & PL & SE & DE & DK & EE & FI & \begin{tabular}{|l|} 
LT \\
\end{tabular} & $\mathbf{L V}$ & NL & NO & PL & SE \\
\hline Mean & 0.35 & 0.43 & \begin{tabular}{|l|}
0.38 \\
\end{tabular} & \begin{tabular}{|l|}
0.35 \\
\end{tabular} & \begin{tabular}{|l|}
0.36 \\
\end{tabular} & 0.37 & \begin{tabular}{|l|}
0.40 \\
\end{tabular} & \begin{tabular}{|l|}
0.40 \\
\end{tabular} & 0.33 & 0.42 & 0.53 & 0.54 & \begin{tabular}{|l|l|}
0.41 \\
\end{tabular} & \begin{tabular}{|l|}
0.44 \\
\end{tabular} & \begin{tabular}{|l|}
0.47 \\
\end{tabular} & \begin{tabular}{|l|}
0.45 \\
\end{tabular} & \begin{tabular}{|l|}
0.50 \\
\end{tabular} & \begin{tabular}{|l|}
0.48 \\
\end{tabular} & \begin{tabular}{|l|}
0.46 \\
\end{tabular} & 0.50 & \begin{tabular}{|l|}
0.12 \\
\end{tabular} & 0.12 & \begin{tabular}{|l|}
0.12 \\
\end{tabular} & \begin{tabular}{|l|}
0.09 \\
\end{tabular} & \begin{tabular}{|l|l|}
0.12 \\
\end{tabular} & 0.12 & 0.10 & \begin{tabular}{|l|}
0.10 \\
\end{tabular} & \begin{tabular}{|l|}
0.10 \\
\end{tabular} & 0.11 \\
\hline SD & 0.26 & 0.31 & 0.29 & 0.24 & \begin{tabular}{|l|}
0.29 \\
\end{tabular} & 0.30 & \begin{tabular}{|l|}
0.31 \\
\end{tabular} & \begin{tabular}{|l|}
0.20 \\
\end{tabular} & 0.25 & 0.22 & 0.31 & 0.31 & 0.35 & 0.35 & \begin{tabular}{|l|} 
\\
\end{tabular} & 0.36 & \begin{tabular}{|l|}
0.32 \\
\end{tabular} & \begin{tabular}{|l|}
0.28 \\
\end{tabular} & \begin{tabular}{|l|}
0.35 \\
\end{tabular} & 0.26 & 0.16 & 0.18 & \begin{tabular}{|l|}
0.19 \\
\end{tabular} & \begin{tabular}{|l|}
0.14 \\
\end{tabular} & \begin{tabular}{|l|}
0.19 \\
\end{tabular} & \begin{tabular}{|l|}
0.18 \\
\end{tabular} & 0.15 & \begin{tabular}{|l|}
0.15 \\
\end{tabular} & \begin{tabular}{|l|}
0.14 \\
\end{tabular} & \begin{tabular}{|l|l|}
0.16 \\
\end{tabular} \\
\hline RSD & 0.74 & 0.72 & 0.76 & 0.70 & \begin{tabular}{|l|} 
\\
\end{tabular} & 0.81 & \begin{tabular}{|l|}
0.78 \\
\end{tabular} & \begin{tabular}{|l|}
0.50 \\
\end{tabular} & \begin{tabular}{|l|}
0.76 \\
\end{tabular} & 0.52 & \begin{tabular}{|l|}
0.58 \\
\end{tabular} & \begin{tabular}{|c|}
0.57 \\
\end{tabular} & \begin{tabular}{|l|}
0.87 \\
\end{tabular} & 0.80 & \begin{tabular}{|l|}
0.77 \\
\end{tabular} & \begin{tabular}{|l|}
0.80 \\
\end{tabular} & \begin{tabular}{|l|}
0.64 \\
\end{tabular} & 0.58 & \begin{tabular}{|l|l|}
0.75 \\
\end{tabular} & 0.53 & 1.42 & 1.52 & 1.56 & 1.60 & 1.52 & \begin{tabular}{|l|}
1.54 \\
\end{tabular} & 1.48 & 1.52 & \begin{tabular}{|l|}
1.45 \\
\end{tabular} & 1.54 \\
\hline
\end{tabular}

These numbers relate future technology; mean is the same as CF of the VRE source.

APPENDIX C: CORRELATIONS BETWEEN THE VRE GENERATION SOURCE

\begin{tabular}{|c|c|c|c|c|c|c|c|c|c|c|c|c|c|c|c|c|c|c|c|c|c|c|c|c|c|c|c|c|c|c|c|}
\hline & & \multicolumn{10}{|c|}{ Onshore wind } & \multicolumn{10}{|c|}{ Offshore wind } & \multicolumn{10}{|c|}{ olar PV } \\
\hline & & & & $\mathbf{E E}$ & FI & \begin{tabular}{|l|l|l|} 
LT & 1
\end{tabular} & $\mathbf{L V}$ & $\mathrm{NL}$ & & L & SE & $\mathrm{DE}$ & DK & EE & FI & LT & $\mathbf{L V}$ & $\mathrm{NL}$ & NO & PL & SE & DE & DK & $\mathbf{E E}$ & FI & \begin{tabular}{l|l} 
LT & L \\
\end{tabular} & LV & NL & NO & PL & SE \\
\hline \multirow{10}{*}{ 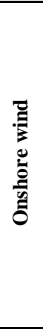 } & & & & & & & & & & 66 & & & & 0.21 & & 33 & & & 0.24 & \begin{tabular}{|l|l|}
0.47 \\
\end{tabular} & \begin{tabular}{|l|}
0.45 \\
\end{tabular} & $-0.27-1$ & \begin{tabular}{l|l}
-0.29 & -- \\
\end{tabular} & -0.28 & -0.28 & & & -0.28 & -0.28 & . & \\
\hline & DK & & & & & & & & & 0 & & & & 3 & & & & & 42 & 51 & 0.63 & $15-15$ & $19-1$ & -0.19 & -0.20 & $18-6$ & & $\mid-0.17$ & 21 & & \\
\hline & $\mathbf{E E}$ & 6 & & & & & & & & & & & & & 0.2 & & & & 15 & 34 & 0.42 & $18-$ & $20 \mid-1$ & -0. & -0.24 & & 23. & \begin{tabular}{|l|}
-0.18 \\
\end{tabular} & 22. & & \\
\hline & FI & & & & & & & & & 19 & & & & & & & & & 21 & & \begin{tabular}{|l|}
0.37 \\
\end{tabular} & $20-$ & $222-6$ & -0.24 & -0.28 & & & -0.21 & & & \\
\hline & LT & & & & & & & & & & & & & & & & & & 13 & & & & & & & & & $\mid-0.19$ & & & \\
\hline & LV & 34 & 34 & & & & & & & 54 & & & & & 0.1 & & & & 16 & & & $-0.18-1$ & $20 \mid-1$ & $|-0.23|-$ & -0.23 & & & -0.18 & & & \\
\hline & NL & & 48 & 19 & & 24 & & & & 38 & 0.2 & 0.67 & ic & 15 & 0.06 & 21 & & 37 & 0.24 & 27. & 29 & $|-0.21|-1$ & & -0.22 & $-0.23 \mid$ & & & -0.23 & & & \\
\hline & NO & & 52 & & & & 30 & & & 0.28 & \begin{tabular}{|l|}
0.65 \\
\end{tabular} & 0.36 & 0 & 0.26 & \begin{tabular}{|l|}
0.26 \\
\end{tabular} & 0 & & 0.26 & \begin{tabular}{|l|}
0.70 \\
\end{tabular} & 0.25 & 0.41 & -0.24 & \begin{tabular}{|c|c}
-0.30 & -0 \\
\end{tabular} & -0.29 & \begin{tabular}{|l|}
-0.34 \\
\end{tabular} & & & \begin{tabular}{|l|}
-0.27 \\
\end{tabular} & & -0.2 & -0 \\
\hline & PL & & 50 & & & & 54 & & & & 0.44 & \begin{tabular}{|l|} 
\\
\end{tabular} & 0 & 0.33 & \begin{tabular}{|l|}
0.08 \\
\end{tabular} & 0 & 50 & 0.28 & \begin{tabular}{|l|l|} 
\\
\end{tabular} & 0.72 & 0.59 & $\mid-0.25$ & \begin{tabular}{l|l}
-0.25 & -0 \\
$-c$
\end{tabular} & $-0.27-$ & \begin{tabular}{|c|} 
\\
\end{tabular} & & & -0.25 & & & -0.27 \\
\hline & SE & & & & & & & & 0.65 & & & & & 19 & & & & & & 45 & & & & -0.32 & & & & & & & \\
\hline \multirow{10}{*}{ 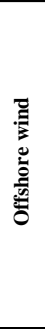 } & DE & & & & & & & & & & & & & 6 & & & & 7 & & & & $09-1$ & & -0.11 & -0.12 & & & & & & \\
\hline & DK & & & & & 31 & & & 0.43 & 50 & \begin{tabular}{|l|}
0.48 \\
\end{tabular} & & & 22 & 8 & 33 & $32 \mid$ & 0.42 & 35 & 57[ & 69 & -0.15 & $9 \mid-6$ & -0.18 & \begin{tabular}{|l|}
-0.18 \\
\end{tabular} & & & $|-0.17|$ & & & -0. \\
\hline & EE & 0.21 & 0.23 & 0.79 & 0.40 & 0.56 & 72 & \begin{tabular}{|l|}
0.15 \\
\end{tabular} & 0.26 & 0.33 & \begin{tabular}{|l|}
0.49 \\
\end{tabular} & \begin{tabular}{|l|}
0.16 \\
\end{tabular} & & & 0.25 & .52 & 0.62 & \begin{tabular}{|l|}
0.11 \\
\end{tabular} & \begin{tabular}{|l|} 
\\
\end{tabular} & \begin{tabular}{|l|}
0.33 \\
\end{tabular} & \begin{tabular}{|l|}
0.43 \\
\end{tabular} & $\mid-0.17-1$ & \begin{tabular}{|l|l}
-0.18 & -0 \\
\end{tabular} & $-0.21-$ & \begin{tabular}{|l|}
-0.22 \\
\end{tabular} & \begin{tabular}{|c|c}
-0.20 & -0 \\
\end{tabular} & -0. & \begin{tabular}{|c|}
-0.17 \\
\end{tabular} & -0.20 & -0.1 & -0.20 \\
\hline & FI & 0.07 & 0.10 & 0.29 & 0.76 & 0.13 & \begin{tabular}{|l|l|}
0.19 \\
\end{tabular} & \begin{tabular}{|l|l|}
0.06 \\
\end{tabular} & 0.26 & \begin{tabular}{|l|l|}
0.08 \\
\end{tabular} & 0.39 & 0.06 & 0.08 & \begin{tabular}{|l|}
0.25 \\
\end{tabular} & & 12 & 0.17 & 0.05 & \begin{tabular}{|l|} 
\\
\end{tabular} & 0.11 & \begin{tabular}{|l|}
0.32 \\
\end{tabular} & \begin{tabular}{|c|c|}
-0.02 & -1 \\
\end{tabular} & \begin{tabular}{l|l|}
-0.04 & -0 \\
\end{tabular} & -0.07 & \begin{tabular}{|c|}
-0.11 \\
\end{tabular} & \begin{tabular}{c|c|c}
-0.06 & -0 \\
\end{tabular} & -0.06 & \begin{tabular}{|l|}
-0.02 \\
\end{tabular} & -0.08 & \begin{tabular}{|c|}
-0.04 \\
\end{tabular} & -0.07 \\
\hline & LT & 0.33 & 0.32 & 0.52 & 0.22 & 0.80 & & \begin{tabular}{|l|}
0.21 \\
\end{tabular} & 0.24 & \begin{tabular}{|l|}
0.59 \\
\end{tabular} & \begin{tabular}{|l|l|} 
\\
\end{tabular} & 0.28 & \begin{tabular}{|l|l|} 
\\
\end{tabular} & 0.52 & \begin{tabular}{|l|l|}
0.12 \\
\end{tabular} & & 0. & \begin{tabular}{|l|}
0.17 \\
\end{tabular} & \begin{tabular}{|l|l|} 
\\
\end{tabular} & 0.60 & \begin{tabular}{|l|}
0.57 \\
\end{tabular} & \begin{tabular}{|c|}
-0.13 \\
-
\end{tabular} & \begin{tabular}{l|l}
-0.15 & -15 \\
\end{tabular} & -0.16 & \begin{tabular}{|c|}
-0.16 \\
\end{tabular} & \begin{tabular}{l|l}
0.15 & -15
\end{tabular} & -0.16 & \begin{tabular}{|c|}
-0.14 \\
\end{tabular} & 0.16 & -0.1 & -0.16 \\
\hline & LV & 0.30 & 0.31 & & & 73 & 84 & & 25 & \begin{tabular}{|l|}
0.50 \\
\end{tabular} & 0.46 & 0.27 & \begin{tabular}{|l|}
0.32 \\
\end{tabular} & 0.62 & \begin{tabular}{|l|l|}
0.17 \\
\end{tabular} & & & 0.17 & 0.13 & 0.54 & \begin{tabular}{|l|l|}
0.56 \\
\end{tabular} & \begin{tabular}{|c|}
-0.11 \\
\end{tabular} & \begin{tabular}{|l|l|l}
-0.13 & -0 \\
\end{tabular} & -0.15 & \begin{tabular}{|}
-0.15 \\
\end{tabular} & \begin{tabular}{l|l}
0.13 & -13
\end{tabular} & -0.14 & \begin{tabular}{|l|}
-0.12 \\
\end{tabular} & 0.14 & -0.1 & -0.15 \\
\hline & NL & 0.62 & 0.42 & & & & & & 26 & \begin{tabular}{|l|}
0.28 \\
\end{tabular} & 0.20 & 0.67 & \begin{tabular}{|l|l|}
0.42 \\
\end{tabular} & 11 & \begin{tabular}{|l|l|} 
\\
\end{tabular} & \begin{tabular}{|l|l|}
0.17 \\
\end{tabular} & & & 0.23 & 0.22 & 26. & $-0.16-$ & \begin{tabular}{|c|c|}
-0.19 & -0 \\
\end{tabular} & -0.17 & \begin{tabular}{|l|}
-0.18 \\
\end{tabular} & -6 & -0.17 & \begin{tabular}{|l|}
-0.18 \\
\end{tabular} & 0.18 & -0.15 & -0.19 \\
\hline & NO & 24 & 0. & & & & & & & \begin{tabular}{|l|}
0.16 \\
\end{tabular} & 0.33 & 0.34 & \begin{tabular}{|l|}
0.35 \\
\end{tabular} & 13 & \begin{tabular}{|l|l|} 
\\
\end{tabular} & 13 & $13 \mid$ & 0. & & 15 & 24 & \begin{tabular}{|c|}
-0.09 \\
-
\end{tabular} & \begin{tabular}{l|l}
-0.13 & -0
\end{tabular} & -0.14 & \begin{tabular}{|l|l|} 
& -0.17 \\
\end{tabular} & -6 & & $\mid-0.11$ & 19 & & -0.17 \\
\hline & PL & & \begin{tabular}{|l|l|} 
\\
\end{tabular} & & & 54 & & & 0.25 & \begin{tabular}{|l|}
0.72 \\
\end{tabular} & 0.45 & 0.47 & 0 & 33 & \begin{tabular}{|l|l|} 
\\
\end{tabular} & & 54 & \begin{tabular}{|l|}
0.22 \\
\end{tabular} & & & 0.78 & -0.09 & $\begin{array}{c}-0.11 \\
-\end{array}$ & $-0.13-$ & \begin{tabular}{|l|} 
\\
\end{tabular} & $13-0$ & & $-0.09 \mid$ & & & -0.12 \\
\hline & SE & & & & & & & & & & 0. & 0.51 & & 0. & \begin{tabular}{|l|l|}
0.32 \\
\end{tabular} & & & \begin{tabular}{|l|}
0.26 \\
\end{tabular} & \begin{tabular}{|l|l|}
0.24 \\
\end{tabular} & & & \begin{tabular}{|c|}
-0.12 \\
\end{tabular} & -8 & -0.16 & \begin{tabular}{|l|l|} 
\\
\end{tabular} & -1 & & -0.13 & & & -0.17 \\
\hline \multirow{10}{*}{. } & DI & & & & & & & & & & & 09 & & $|-0.17|$ & $-0.02 \mid$ & & & -0. & & 09 & & & & 0.88 & & $\begin{array}{lll}30 & 0 \\
\end{array}$ & & & & & 0.92 \\
\hline & DK & 29. & $-0.19 \mid$ & & 22. & 20. & & .24 & 30 & & -0.31 & -0.13 & -0 & $\mid-0.18$ & 0.04 & -0 & & $|-0.19|$ & -0.13 & -0 & $|-0.15|$ & \begin{tabular}{|l|} 
\\
\end{tabular} & & 0.88 & \begin{tabular}{|l|}
0.88 \\
\end{tabular} & & & & & & \\
\hline & $\mathbf{E E}$ & 0.28 & -0.19 & & -0.24 & 0.24 & & \begin{tabular}{|l|}
-0.22 \\
\end{tabular} & \begin{tabular}{|l|}
-0.29 \\
\end{tabular} & \begin{tabular}{|c|}
-0.27 \\
\end{tabular} & -0.32 & -0.11 & -0. & \begin{tabular}{|l|}
-0.21 \\
\end{tabular} & \begin{tabular}{|c|}
$\mid-0.07$ \\
\end{tabular} & -0 & -0. & \begin{tabular}{|l|}
-0.17 \\
\end{tabular} & \begin{tabular}{|l|l|} 
\\
\end{tabular} & -0. & \begin{tabular}{|c|}
-0.16 \\
\end{tabular} & \begin{tabular}{|c|}
0.88 \\
\end{tabular} & & & & 95 & & & & & 0.93 \\
\hline & FI & -0.28 & $-0.20 \mid$ & & -0.28 & \begin{tabular}{|c|}
-0.24 \\
\end{tabular} & & \begin{tabular}{|l|}
-0.23 \\
\end{tabular} & \begin{tabular}{|l|}
-0.34 \\
\end{tabular} & $27-$ & \begin{tabular}{|c|}
-0.35 \\
\end{tabular} & \begin{tabular}{|l|}
-0.12 \\
\end{tabular} & -0. & \begin{tabular}{|l|}
-0.22 \\
\end{tabular} & \begin{tabular}{|c|}
-0.11 \\
\end{tabular} & -0 & \begin{tabular}{|c|}
-0.15 \\
\end{tabular} & \begin{tabular}{|l|}
-0.18 \\
\end{tabular} & \begin{tabular}{|c|}
-0.17 \\
\end{tabular} & \begin{tabular}{|c|}
-0.13 \\
\end{tabular} & \begin{tabular}{|c|}
-0.17 \\
\end{tabular} & \begin{tabular}{|l|}
0.86 \\
\end{tabular} & $88 \quad 0$ & & & $\begin{array}{l}0.93 \\
0\end{array}$ & & & & & .95 \\
\hline & $\mathbf{L T}$ & $-0.28-$ & \begin{tabular}{|l|}
-0.18 \\
\end{tabular} & & -0.23 & \begin{tabular}{|l|}
-0.23 \\
\end{tabular} & & \begin{tabular}{|l|}
-0.21 \\
\end{tabular} & $|-0.27|$ & \begin{tabular}{|c|}
-0.28 \\
\end{tabular} & -0.31 & -0.10 & $|-0.17|$ & \begin{tabular}{|c|}
-0.20 \\
\end{tabular} & $|-0.06|$ & \begin{tabular}{|l|}
-0.15 \\
\end{tabular} & \begin{tabular}{|c|}
-0.13 \\
\end{tabular} & \begin{tabular}{|l|}
-0.17 \\
\end{tabular} & -0.13 & \begin{tabular}{|c|}
-0.13 \\
\end{tabular} & \begin{tabular}{|c|}
-0.15 \\
\end{tabular} & \begin{tabular}{|c|}
0.90 \\
\end{tabular} & \begin{tabular}{l|l}
0.89 & 0 \\
\end{tabular} & 0.95 & 0.93 & & 0.98 & \begin{tabular}{|l|}
0.86 \\
\end{tabular} & 91 & & .93 \\
\hline & LV & 0.2 & \begin{tabular}{|l|}
-0.19 \\
\end{tabular} & & -0.24 & -0.24 & & \begin{tabular}{|l|}
-0.22 \\
\end{tabular} & -0.28 & \begin{tabular}{|c|}
-0.28 \\
\end{tabular} & $\mid-0.32$ & $|-0.10|$ & $|-0.17|$ & \begin{tabular}{|l|}
-0.21 \\
\end{tabular} & $|-0.06|$ & \begin{tabular}{|l|}
-0.16 \\
\end{tabular} & $|-0.14|$ & \begin{tabular}{|l|}
-0.17 \\
\end{tabular} & $\mid-0.13$ & \begin{tabular}{|c|}
-0.13 \\
\end{tabular} & \begin{tabular}{|c|}
-0.15 \\
\end{tabular} & \begin{tabular}{|l|}
0.89 \\
\end{tabular} & $\begin{array}{l} \\
\end{array}$ & 8 & 0.94 & 98 & & 0.8 & & & .93 \\
\hline & NL & & -0.1 & & & & & -0. & -0.2 & & -0 & $|-0.11|$ & & -0. & $-0.02 \mid$ & & & -0. & -0. & 09 & $|-0.13|$ & & & & 0.84 & & & & & & \\
\hline & NO & & -0.2 & & & -0 & & -0 & $|-0.01|$ & -0.2 & & $|-0.12|$ & & -0. & $-0.08 \mid$ & & & $\begin{array}{l}-0.18 \\
\end{array}$ & -0. & & -0.11 & & & & & & & & & 0.92 & \\
\hline & PL & & $\mid-0.16$ & & $\mid-0$. & $0.21-1$ & & -0. & $|-0.25|$ & -0.2 & -0 & $\mid-0.08$ & -0. & 0 & $\left.\right|^{-10}$ & & & -0 & & & -0.1 & & & & & & & & & & \\
\hline & & & & \begin{tabular}{|l|}
-0.22 \\
\end{tabular} & & $-0.22 \mid-$ & & & \begin{tabular}{|c||}
-0.34 \\
\end{tabular} & $|-0.27|$ & & & & & & & & & & & & \begin{tabular}{|l|}
0.92 \\
\end{tabular} & & & & & & & & & \\
\hline
\end{tabular}

APPENDIX D: WEIGHTS IN THE SCENARIOS

\begin{tabular}{|c|c|c|c|c|c|c|c|c|c|c|c|c|c|c|c|c|c|c|c|c|c|c|c|c|c|c|c|c|c|c|}
\hline & \multicolumn{10}{|c|}{ Onshore wind } & \multicolumn{10}{|c|}{ Offshore wind } & \multicolumn{10}{|c|}{ Solar PV } \\
\hline Installed generation $(\mathbf{G W})$ & DE & DK & $\mathbf{E E}$ & FI & LT & $\mathbf{L V}$ & NL & No & PL & SE & $\mathbf{D E}$ & DK & EE & FI & LT & $\mathbf{L V}$ & NL & NO & PL & SE & DE & DK & $\mathbf{E E}$ & FI & LT & LV & NL & No & PL & SE \\
\hline Today & 45.0 & 4.0 & 0.4 & 1.4 & 0.4 & 0.1 & 3.5 & 0.9 & 5.7 & 6.0 & 4.1 & 1.3 & 0.0 & 0.0 & 0.0 & 0.0 & 0.6 & 0.0 & 0.0 & 0.0 & 39.8 & 0.9 & 0.4 & 0.0 & 0.1 & 0.0 & 1.0 & 0.0 & 0.2 & 0.0 \\
\hline Today doubled & 90.0 & 8.0 & 0.8 & 2.9 & 0.9 & 0.1 & 7.0 & 1.7 & 11.4 & 12.1 & 8.2 & 2.5 & 0.0 & 0.0 & 0.0 & 0.0 & 1.3 & 0.0 & 0.0 & 0.0 & 79.6 & 1.7 & 0.8 & 0.0 & \begin{tabular}{|l}
0.1 \\
\end{tabular} & 0.0 & 2.1 & \begin{tabular}{|l}
0.0 \\
\end{tabular} & \begin{tabular}{|l|l}
0.4 \\
\end{tabular} & 0.0 \\
\hline $\begin{array}{c}\text { Optimized (existing } \\
\text { installations) }\end{array}$ & 45.0 & 4.0 & 2.0 & 10.0 & 2.0 & 2.0 & 3.5 & 11.0 & 5.7 & 13.0 & 4.1 & 6.1 & 1.2 & 2.0 & 1.2 & 1.2 & 9.7 & 5.0 & 1.6 & 2.0 & 39.8 & 5.0 & 2.0 & 5.0 & 2.0 & 2.0 & 11.5 & 5.0 & 4.8 & 5.0 \\
\hline $\begin{array}{c}\text { Optimized (future } \\
\text { technology) }\end{array}$ & 45.0 & 4.0 & 1.0 & 10.0 & 0.4 & 0.1 & 3.5 & 11.0 & 5.7 & 8.1 & 4.1 & 1.3 & 1.2 & 2.0 & 0.0 & 0.0 & 0.6 & 5.0 & 0.0 & 0.0 & 39.8 & 4.0 & 2.0 & 5.0 & \begin{tabular}{|l|}
0.1 \\
\end{tabular} & 2.0 & 1.0 & 5.0 & 0.2 & 5.0 \\
\hline
\end{tabular}

